\title{
Transplantation of GMP-grade human iPSC-derived retinal pigment epithelial cells in rodent model: the first pre-clinical study for safety and efficacy in China
}

\author{
Hang Zhang ${ }^{1,2 \#}$, Bingnan Su ${ }^{1 \#}$, Luyan Jiao ${ }^{3 \#}$, Ze-Hua Xu ${ }^{2}$, Chang-Jun Zhang ${ }^{2}$, Jinfu Nie ${ }^{4}$ Mei-Ling Gao ${ }^{2}$, \\ Ying V. Zhang ${ }^{3}$, Zi-Bing Jin ${ }^{1,5}$ \\ ${ }^{1}$ Beijing Institute of Ophthalmology, Beijing Tongren Eye Center, Beijing Tongren Hospital, Capital Medical University, Beijing Ophthalmology \\ \& Visual Sciences Key Laboratory, Beijing, China; ${ }^{2}$ Laboratory of Stem Cell \& Retinal Regeneration, Institute of Stem Cell Research, The Eye \\ Hospital, Wenzhou Medical University, Wenzhou, China; ${ }^{3}$ Nuwacell Biotechnologies Co., Ltd, Hefei, China; ${ }^{4}$ Center of Medical Physics and \\ Technology, Hefei Institutes of Physical Science, Chinese Academy of Sciences, Hefei, China; ${ }^{5}$ National Center for International Research in \\ Regenerative Medicine and Neurogenetics, Wenzhou Medical University, Wenzhou, China \\ Contributions: (I) Conception and design: ZB Jin, ML Gao, YV Zhang; (II) Administrative support: ZB Jin, YV Zhang; (III) Provision of study \\ materials: ZB Jin, YV Zhang; (IV) Collection and assembly of data: H Zhang, L Jiao, B Su, ZH Xu, CJ Zhang, J Nie; (V) Data analysis and \\ interpretation: H Zhang, ML Gao, ZB Jin, B Su, YV Zhang; (VI) Manuscript writing: All authors; (VII) Final approval of manuscript: All authors. \\ \#These authors contributed equally to this work. \\ Correspondence to: Zi-Bing Jin. Beijing Institute of Ophthalmology, Beijing Tongren Eye Center, Beijing Tongren Hospital, Capital Medical \\ University, Beijing Ophthalmology \& Visual Sciences Key Laboratory, Beijing, China. Email: jinzibing@foxmail.com; Ying V. Zhang. Nuwacell \\ Biotechnologies Co., Ltd, Hefei, China. Email: yzhang@nuwacell.com; Mei-Ling Gao. Laboratory of Stem Cell \& Retinal Regeneration, Institute of \\ Stem Cell Research, The Eye Hospital, Wenzhou Medical University, Wenzhou, China. Email: gaoml@wmu.edu.cn.
}

Background: Age-related macular degeneration (AMD) is the leading cause of blindness in the elderly due in large part to age-dependent atrophy of retinal pigment epithelium (RPE) cells. RPE cells form a monolayer located between the choroid and the outer segments of photoreceptors, playing multifarious roles in maintenance of visual function. Allogeneically induced pluripotent stem cell-derived RPE (iPSC-RPE or iRPE) has become a potential approach for providing an abundant source of donors for clinical cell products. Transplantation of iRPE has been proven effective in rescuing impaired retinas in Royal College of Surgeons (RCS) rats after approximately 5 to 6 weeks. Here, we explore the long-term (19 weeks) safety and efficacy of human iRPE cell transplantation in pre-clinical animal models.

Methods: The expression of human RPE-specific markers in iRPE cells was determined using immunofluorescence staining. For the proliferative test, Ki-67 expression was also verified by immunofluorescence and flow cytometric analysis. Then, iRPE cells were transplanted into the subretinal space of immune-deficient NOD/SCID/IL-2 Rgc ${ }^{\text {null }}$ (NSG) mice to assess their safety. To evaluate whether the transplanted cells could survive and rescue visual function, we performed color fundus photography, focal electroretinogram and immunostaining after delivering iRPE cells into the subretinal space of RCS rats.

Results: Human iRPE cells expressed native RPE-specific markers, such as microphthalmia-associated transcription factor (MiTF), retinal pigment epithelium-specific 65-kDa protein (RPE65) and tight-junction associated structural protein (ZO-1), and their proliferative capacity (Ki-67 expression) was poor after 25 days of induction. A tumorigenicity test revealed no tumor formation or abnormal proliferation in the immunodeficient mice after subretinal injection of $5 \times 10^{5}$ iRPE cells. The transplanted iRPE cells survived for at least 19 weeks and maintained visual function for 15 weeks.

Conclusions: In the present study, we provided further evidence for the use of human iRPE transplantation to treat retinal degenerative disease in pre-clinical animal models. Therefore, we consider human iRPE cells a promising source of cell replacement therapy for AMD. 
Keywords: GMP grade; human iPSCs; RPE cells; pre-clinical study; transplantation; tumorigenicity

Submitted Jun 14, 2020. Accepted for publication Nov 08, 2020.

doi: $10.21037 / \mathrm{atm}-20-4707$

View this article at: http://dx.doi.org/10.21037/atm-20-4707

\section{Introduction}

Age-related macular degeneration (AMD) is the leading cause of visual loss in the elderly over 60 years old (1). As the population ages, the prevalence of AMD is likely to result in a substantial economic burden for health services and nursing worldwide. AMD is a complex disease caused by a combination of genetic and environmental factors. Cell atrophy of the retinal pigment epithelium (RPE) in AMD leads to irreversible vision loss, especially loss of central visual acuity. There are some treatments to help slow disease progression and alleviate symptoms, but no more effective options are currently available (2).

RPE, a monolayer of cells, is located between the choroid and the outer segments of photoreceptors and plays various important physiological roles in the maintenance of visual function, including forming the blood-retina barrier, transferring metabolic products and nutrients, secreting growth factors and immunosuppressive factors, and contributing to the visual cycle and phagocytosis of the mature photoreceptor outer segment (POS) (3). Dysfunction of RPE cells can impact retinal structure or function and lead to the loss of visual performance or even blindness.

Currently, cell-based replacement therapy is considered a potential method for dry AMD, along with geographic atrophy and a reduction in RPE density. This treatment is expected to replace atrophic or dead RPE with healthy RPE cells, remedy the damaged function of degenerative RPE, and then preserve or restore visual function. Over two decades, RPE replacement therapy has undergone progressive development. A pioneering study involving transplantation of human fetal RPE into the subretinal space of AMD patients demonstrated tolerance for human RPE allografts with an intact blood-retina barrier (4). Autologous transplantation of RPE cells has been reported to improve reading acuity for AMD patients $(5,6)$. These studies have provided a proof-of-concept for RPE transplantation for the treatment of AMD.

In addition, various studies on RPE cell replacement therapy have been performed in animal models using embryonic stem cell- or induced pluripotent stem cell- derived RPE cells (ESC- or iPSC-RPE) (7-10). Visual function has been improved by transplantation of ESC- or iPSC-RPE into Royal College of Surgeons (RCS) rats and nonhuman primates (11-15). However, tumorigenicity is still the greatest concern when planning clinical trials for each research group, although others have provided strong evidence that ESC- or iPSC-RPE cell transplantation has a negligible risk of tumor formation (15-17). Phase I clinical trials have been launched for safety testing in several countries (18). Currently, the efficacy of ESCor iPSC-RPE cell transplantation needs to be studied $(19,20)$. The aims of this study were to assess the safety of induced pluripotent stem cell-derived RPE (iPSC-RPE or iRPE) cell transplantation, test the long-term cell survival of xenotransplants and rescue visual function in a retinal degenerative rat model prior to a clinical trial.

We present the following article in accordance with the ARRIVE reporting checklist (available at http://dx.doi. org/10.21037/atm-20-4707).

\section{Methods}

\section{Animals}

Pigmented RCS rats, a classical model of retinal degeneration (RD), were from JOINN Laboratories (Suzhou, China). NOD/SCID/IL-2Rgc ${ }^{\text {null }}$ (NSG) mice, immunodeficient animal models, were obtained from Shanghai Model Organisms. The animals, 5 in each cage, were maintained in a common room with controlled temperature, humidity and 12-h light/dark cycles. All experimental animals were provided free access to food and water. Experiments were performed under a project license (\#NC2018R012) granted by Institutional Ethics Committee in compliance with institutional guidelines for the care and use of animals.

\section{Good manufacturing practice (GMP)-compatible facility and operation}

Peripheral blood mononuclear cell (PBMC) collection, iPSC derivation and propagation, and iRPE differentiation 
were performed in a GMP-compatible facility at Nuwacell Biotechnologies. All cells used in this study were handled by qualified personnel. GMP-compatible standard operating procedures were followed. The facility and equipment were routinely cleaned, calibrated, and monitored rigorously by contract vendors. All materials used were qualified according to the supplier certificate of analysis and internal qualification. Inventory records, the generation and distribution of materials were documented.

\section{Generation of GMP-compatible iPSCs}

PBMCs in $8 \mathrm{ml}$ of peripheral blood were collected from healthy donors with written consent under approval from the Ethics Committee at Nuwacell Biotechnologies. PBMCs $\left(2 \times 10^{6}\right)$ were cultured in erythroid progenitor growth medium (EPGM) for 10 days to achieve over $5 \times 10^{6} \mathrm{CD} 71^{+} / \mathrm{CD} 235 \mathrm{a}^{+}$erythroid progenitors (EPs) with a purity greater than $90 \%$. A total of $1 \times 10^{6}$ freshly expanded EPs were nucleofected with a cocktail of proprietary GMP-compatible episomal reprogramming vectors encoding OCT4, NANOG, SOX2, LIN28, and other auxiliary elements. Transfected EPs were cultured in EP reprogramming medium (EPRM) and subsequently in ncEpic hPSC medium (Nuwacell Biotechnologies) upon the appearance of iPSC colonies for $\sim 10$ days. A total of 12 iPSC clones were selected, purified, and expanded until passage 3. For each donor, 3 iPSC clones were further propagated according to the GMP-compatible iPSC banking procedure to establish the seed cell bank (SCB), master cell bank (MCB), and working cell bank (WCB) when GMP-compatible qualifications were carried out at each banking step.

\section{Generation of GMP-compatible iRPE cells}

GMP-compatible iRPE cells were differentiated from iPSCs revived from the WCB in a 4-step differentiation process modified from previously published methods (21). Revived iPSCs were cultured on vitronectin (VTN, Nuwacell Biotechnologies) for 2 days in ncEpic hPSC medium (Nuwacell Biotechnologies). On day 0 of differentiation, the culture medium was changed to RPE priming medium (RPM, Nuwacell Biotechnologies) with daily feeding. On day 2, the medium was changed to RPE induction medium (RIM) with daily feeding. On day 7, the medium was changed to RPE differentiation medium (RDM, Nuwacell Biotechnologies) with daily feeding. On day
17 , the medium was changed to RPE maturation medium (RMM) with feeding every other day. On days 21-25, iRPE differentiation culture underwent in-process purification. iRPEs were processed for GMP-compatible cryobanking and qualification on days 26-30 of differentiation. Mature iRPE cells were grown from revived iPRE progenitors in RMM medium and used for the next steps.

\section{Culture of GMP-grade buman iRPE cells}

Human iRPE cells supplied by Nuwacell Biotechnologies, were maintained in RPE maintenance medium containing $10 \mathrm{mM}$ Nuwacell $^{\mathrm{TM}}$ Blebbistatin (Nuwacell Biotechnologies) on VTN-coated 6-well plates, with medium changes every $48 \mathrm{~h}$. All processes were performed in accordance with institutional guidelines approved by the institutional ethics committee.

\section{Quantitative real-time PCR (qPCR)}

Total RNA was isolated using the RNAprep Pure Cell/ Bacteria Kit (Tiangen) per the manufacturer's protocol. RNA was quantified using an ND-100 spectrophotometer (Nanodrop Technologies). Synthesized cDNAs and custom-made 24 RPE gene array plates were purchased from Bio-Rad. SYBR Green-based qPCR was run on a LightCycler480 II Real-Time PCR System (Roche) according to the manufacturer's protocol. Each sample was run with at least 3 biological replicates, and the data were analyzed in $\mathrm{R}$ software.

\section{Whole-genome sequencing and bioinformatics analysis}

A 150 bp paired-ended whole-genome sample sequencing library was prepared and sequenced on an Illumina $\mathrm{X}$ Ten platform with 50X coverage. The clean data were produced by filtering raw data. All clean data from each sample were mapped to the human reference genome. Burrows-Wheeler Aligner (BWA v0.7.15) software was used to perform the alignment. Single-sample genomic variations, including single nucleotide polymorphisms (SNPs) and small insertions or deletions (InDels), were detected by HaplotypeCaller of GATK (v3.7) following the recommendation of best practices for variant analysis with the Genome Analysis Toolkit (GATK, https://www. broadinstitute.org/gatk/guide/bestpractices). iRPE $v s$. Donor EP and iPSC MCB vs. Donor EP somatic variant calling were performed with GATK Mutect2. In addition 
to SNPs and InDels, copy number variants (CNVs) were called with CNVKit (v0.9.3), and structural variants (SVs) were called with Delly (v0.8.3). All variant annotations were performed with ANNOVAR. The variants were filtered with a variety of databases, such as COSMIC, ClinVar and dbVar.

\section{Immunofluorescence staining}

For immunostaining, iRPE cells were seeded on VTNcoated 8-chambered slides in RMM. After culture for 10-20 days, the cells were washed with Dulbecco's phosphate-buffered saline (DPBS) and fixed with $4 \%$ paraformaldehyde (PFA) in $0.1 \mathrm{M}$ sodium cacodylate buffer ( $\mathrm{pH} 7.4$ ) for $15 \mathrm{~min}$ at $4{ }^{\circ} \mathrm{C}$. The fixed cells were then washed with $1 \times$ DPBS, blocked, and permeabilized with $1 \times$ DPBS containing $5 \%$ bovine serum albumin (BSA) and $0.2 \%$ Triton $\mathrm{X}-100$ for $1 \mathrm{~h}$ at $4{ }^{\circ} \mathrm{C}$. The cells were then labeled with primary antibodies in $1 \times$ DPBS with $5 \%$ BSA overnight at $4{ }^{\circ} \mathrm{C}$. Following 3 washes with DPBS, the cells were incubated with the appropriate Alexa Fluor-conjugated secondary antibody for $1 \mathrm{~h}$ at $4^{\circ} \mathrm{C}$. The cells were imaged using either an Olympus BX51 upright microscope or an Olympus Fluo-View 1000 spectral confocal microscope.

For preparation of sections for immunostaining, the eyes were removed and fixed in 4\% PFA for $1 \mathrm{~h}$, dehydrated twice in $30 \%$ sucrose, embedded in optimal cutting temperature compound (OCT) and sectioned at a $12-\mu \mathrm{m}$ thickness using a freezing microtome. The sections were blocked and permeabilized with phosphate-buffered saline (PBS) containing 4\% BSA and $0.5 \%$ Triton X-100 for $1 \mathrm{~h}$ at room temperature (RT). Primary antibodies were incubated for $12 \mathrm{~h}$ at $4{ }^{\circ} \mathrm{C}$ and washed three times with PBS at RT. Secondary antibodies were incubated for $1 \mathrm{~h}$ at RT, and nucleic acids were labeled with 4',6-diamidino2-phenylindole (DAPI) for $10 \mathrm{~min}$ at RT. Antibodies were diluted with PBS containing $1 \%$ BSA and $0.5 \%$ Triton $\mathrm{X}-100$. The following antibodies were used: rabbit antiRPE65 (Abcam, \#ab235950, 1:100), rabbit anti-ZO1 (Thermo Fisher, \#18-7430, 1:500), mouse anti-ZO1 (Invitrogen, \#339100, 1:100), mouse anti-MiTF (Abcam, \#ab3201, 1:500), mouse anti-MiTF (Exalpha, \#X1405M, 1:100), mouse anti-Ki67 (BD, \#6280947, 1:100), mouse anti-human nuclear antibody (Abcam, \#ab191181, 1:100), donkey anti-rabbit 488 (Jackson, \#711-545-152, 1:400), donkey anti-mouse 594 (Jackson, \#715-585-151, 1:400), goat anti-rabbit 594 (Invitrogen, \#A11012, 1:300), and goat anti-mouse 488 (Invitrogen, \#A11029, 1:300). Images were taken by a Leica confocal laser-scanning microscope (Leica SP8, Germany).

\section{Flow cytometry}

For flow cytometric analysis, Nuwacell ${ }^{\mathrm{TM}}$ iRPE cells were dissociated with TrypLE Express for $7 \mathrm{~min}$ at $37{ }^{\circ} \mathrm{C}$. Single cells were fixed in $4 \% \mathrm{PFA}$ for $10 \mathrm{~min}$, permeabilized in $0.1 \%$ Triton $\mathrm{X}-100$ for $5 \mathrm{~min}$, and blocked in $3 \%$ fetal bovine serum for $30 \mathrm{~min}$. Then, the cells were incubated with primary antibodies and secondary antibodies or fluorochrome-conjugated antibodies followed by washes with fluorescence-activated cell sorting (FACS) buffer and resuspension in DPBS. The following antibodies were used: fluorochrome-conjugated antibodies Ki-67 (BD, \#558615, 1:10), rabbit anti-Otx2 (Sigma, \#HPA000633, 1:500), rabbit anti-BEST1 (Abcam, \#ab14927, 1:100), mouse anti-MiTF (Abcam, \#ab3201, 1:100), rabbit anti-RPE65 (Abcam, \#ab235950, 1:100), mouse anti-RPE65 (Abcam, \#ab13826, 1:100), rabbit anti-ZO1 (Thermo Fisher, \#18-7430, 1:100), goat anti-rabbit APC (Abcam, \#ab130805, 1:300), and goat anti-mouse FITC (Abcam, \#ab6785, 1:300). The samples were analyzed with a flow cytometer (FACS Calibur, BD Biosciences), and data were further analyzed with FlowJo software.

\section{Subretinal transplantation}

At P21, RCS rats were anesthetized with chloral hydrate (300 $\mathrm{mg} / \mathrm{kg}$ ) after dilating the pupils with compound tropicamide eye drops. Human iRPE cell suspension was transplanted into the subretinal space with a blunt $5-\mu \mathrm{L}$ Hamilton needle. In total, $2 \mu \mathrm{L}$ of cell suspension at a concentration of $2.5 \times 10^{4}$ cells $/ \mu \mathrm{L}$ in PBS was injected into the right eye, with an equal volume of PBS into the fellow eye of 19 rats as a sham control and other unhandled eyes from 3 rats as untreated controls. All experimental rats were supplied with drinking water with dissolved cyclosporine A $(210 \mathrm{mg} / \mathrm{L})$ from the day of surgery to the end of the study. Five-week-old NSG mice were anesthetized with pentobarbital sodium $(75 \mathrm{mg} / \mathrm{kg})$ following dilation of the pupils. Then, several doses of iPSC or human iRPE cell suspensions were delivered into the subretinal space as mentioned above.

\section{Focal electroretinogram recording}

Focal electroretinogram (ERG) was used to assess focal retinal function by manual instruments (Phoenix Research 
Labs). After dark adaption overnight, RCS rats were anesthetized using chloral hydrate $(300 \mathrm{mg} / \mathrm{kg})$ with the pupils dilated using compound tropicamide eye drops. Three separate electrodes were used: the head electrode and the ground electrode were fixed onto subcutaneous tissue of the forehead and tail, respectively, and another ring electrode was embedded in the cornea contact lens. The RCS rats were placed on a heating pad to keep the body temperature from dropping. ERG was carried out under dark-adapted conditions.

\section{Statistical analysis}

The results were analyzed using SPSS 22 and are presented as the mean \pm SEM using GraphPad Prism 5.0. Statistical comparisons were performed by unpaired $t$-tests. $\mathrm{P}<0.05$ was considered significantly different.

\section{Results}

\section{Efficient differentiation and characterization of clinical- grade iRPE cells}

Multiple groups have reported various methods of generating research- and clinical-grade RPE cells from human pluripotent stem cells (21-25). Here, we developed a GMP-compatible process to manufacture clinical-grade iRPE cells from human iPSCs (Figure 1A). iPSCs were generated from $\mathrm{CD} 71^{+} / \mathrm{CD} 235 \mathrm{a}^{+}$erythroid progenitors using a clinical-grade episomal reprogramming process [Figure $1 A$ and (26)]. The GMP-compatible iPSC banks were established and tested in compliance with standards found in a collection of clinical-grade human pluripotent stem cell derivation reports (27-35) and subjected to additional genome stability tests to ensure suitability for future clinical use (36-41). The iPSC cryobanks were used for identity, viability, genetic stability, potency, and microbiological safety tests, each of which passed the acceptance criteria (Table S1).

To generate iRPE cells, we combined low-level dualSMAD inhibition (23) and fibroblast growth factor (FGF) inhibition (22) to convert iPSCs into the primed neuroectoderm lineage and utilized additional cytokines, such as activin-A, nicotinamide, and prostaglandin $\mathrm{E} 2$, to predispose the neural progenitors to assume an RPE fate upon further differentiation (Figure 1B). The expression of specific molecules associated with cellular function in mature RPEs was investigated by qPCR, flow cytometry and immunocytochemistry. The mRNA levels of microphthalmia-associated transcription factor (MiTF), the eye field transcription factors TLL1 and LHX2, RPEspecific $65-\mathrm{kDa}$ protein (RPE65), and mature markers of RPE, including bestrophin-1 (Best1), visual cycle protein cellular retinaldehyde-binding protein (CRALBP), cell junction protein ZO-1, Mer tyrosine kinase-phagocytosis MERTK, and RPE secreted factor PEDF, were abundant in iRPE cells (Figure 1C). By day 20 of differentiation, pigmentation started to appear in immature iRPE cells with the typical cobblestone morphology, and by 40 days of the differentiation process, large pigmented areas were visible in the culture with the naked eye (Figure 1Da-b). Immunostaining microscopy confirmed that the mature iRPE cells expressed the RPE-specific markers MiTF and ZO-1 (Figure 1Dc-e). Furthermore, flow cytometric analyses showed that iRPE cells coexpressed MiTF/ZO-1, RPE65/ZO-1, and Best1/Otx2 at a level greater than 95\% (Figure 1E).

To assess the genomic stability of GMP-grade iPSCs (MCBs) and downstream iRPE cells, we performed wholegenome sequencing and analysis of donor EP cells, iPSCs (MCBs) and iRPEs (Figure 2A). Somatic variance analysis among three cell samples showed no pathogenic SVs, CNVs, SNVs or InDels. Furthermore, no somatic variants were found within Cosmic-defined tier-one-level genes from the Cancer Gene Census (Figure 2B,C).

In summary, we generated clinical-grade iPSC cryobanks and immature iRPE cryobanks in GMP-compatible procedures. iRPE identity and purity were confirmed by marker expression, followed by further pre-clinical testing.

\section{Culture and identification of iRPE cells before transplantation}

Human iRPE cells were thawed and maintained on vitronectin-coated 6-well plates and were identified at several time points (Figure 3). On the second day (D2) after recovery, most iRPE cells showed an immature fusiform or oval appearance (Figure 3B). Over time, typical clusters with a cobblestone morphology were observed on D8 (Figure 3C). With continued progress, the iRPE cells exhibited the appearance of mature, tight-junction and hexagonal monolayer epithelium with slight pigmentation. The cells were allowed to culture for an additional several days and used for further analysis or transplantation (Figure 3D). After induction for 25 days, the iRPE cells were matured with brown pigmentation (Figure $3 E$ ). To identify iRPE 
A Pipeline for manufacturing and preclinical testing of clinical-grade iRPE

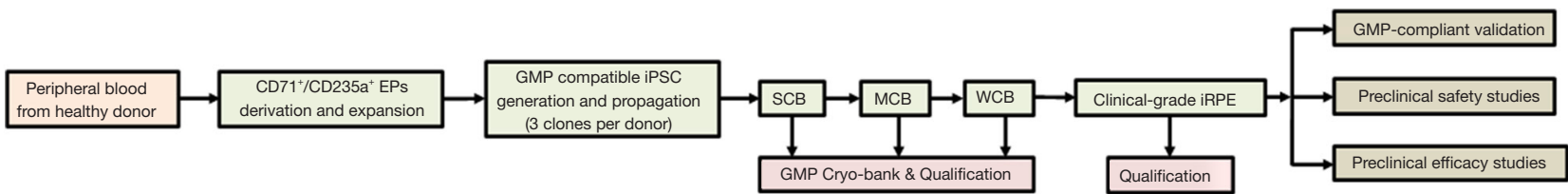

B Clinical-grade iRPE differentiation procedure (40 days)

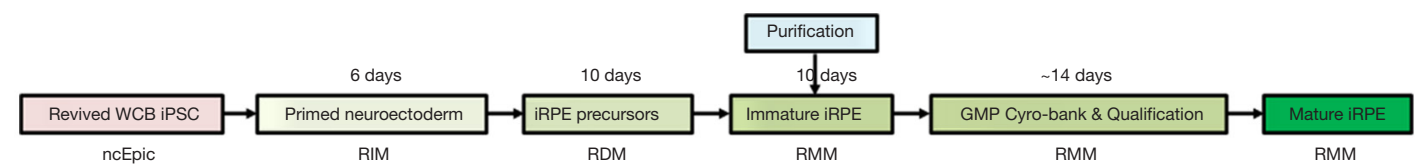

C

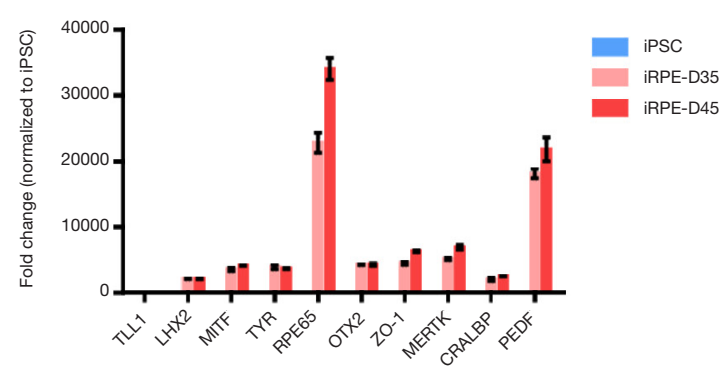

E

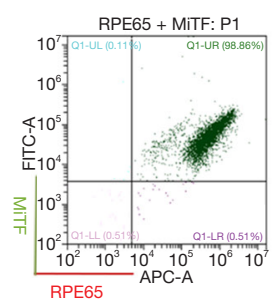

RPE markers

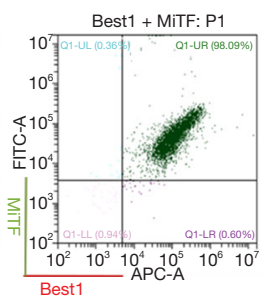

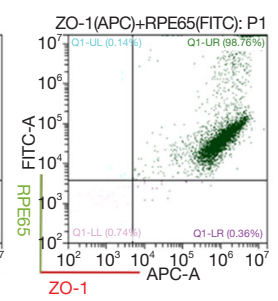
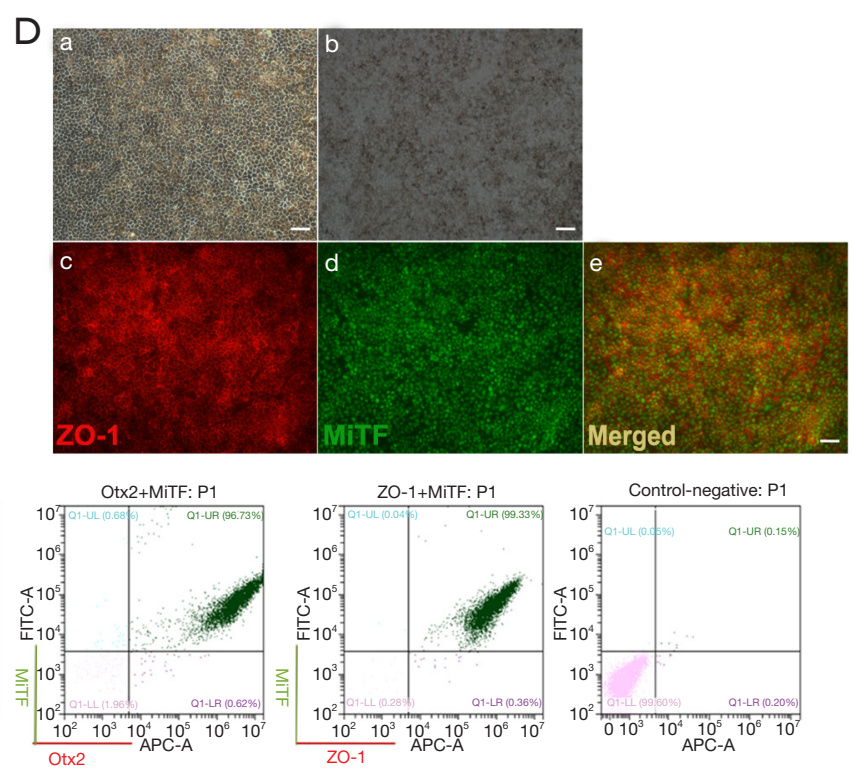

Figure 1 Maturation and characterization of human iRPE cells. (A) Scheme of GMP-compatible processes to manufacture and test clinicalgrade iPSCs and iRPE cells for preclinical studies. (B) Timeline of manufacturing clinical-grade iRPE cells from iPSC WCB. A GMPcompatible immature iRPE master cell bank was established 26 days from the start of monolayer iPSC differentiation, and all reagents used were xeno-free and chemically defined. (C) Gene expression analysis of known RPE-specific genes of iRPE cells collected on days 35 and 45 of differentiation. (D) Top panel: Bright field images of the iRPEs in monolayer on days 20 and 40 of differentiation. Bottom panel: Immunostaining of the mature iRPE (day 40) markers ZO-1 (red) and MiTF (green). Scale bars, $100 \mu \mathrm{m}$. (E) Flow cytometric analysis of mature iRPE cells (day 40) costained for MiTF/RPE65, MiTF/Best1, RPE65/ZO-1, MiTF/Otx2, and MiTF/ZO-1. WCB, working cell bank; RIM, RPE induction medium; RDM, RPE differentiation medium; RMM, RPE maturation medium.

before transplantation, we confirmed the expression of RPE-specific proteins, including RPE65 and MiTF, which are required for retinoid recycling and melanogenesis, with immunofluorescence staining (Figure $3 G, L$ ). ZO-1 was also positive on the lateral margins of the mature iRPE cells (Figure 3H-7). After maintenance for 25 days, human iRPE cells presented pigments and RPE-specific protein expression.

\section{Proliferation analysis of human iRPE cells}

To decrease the possibility of tumorigenicity, we used Ki67 expression to assess the proliferative capacity of human iRPE cells. Immunofluorescence of the iRPE cells showed that approximately one-quarter of the cells were Ki-67 positive at D15 (Figure 4). As the cells were kept in RPE maintenance medium for 10 more days, few cells were Ki- 
A

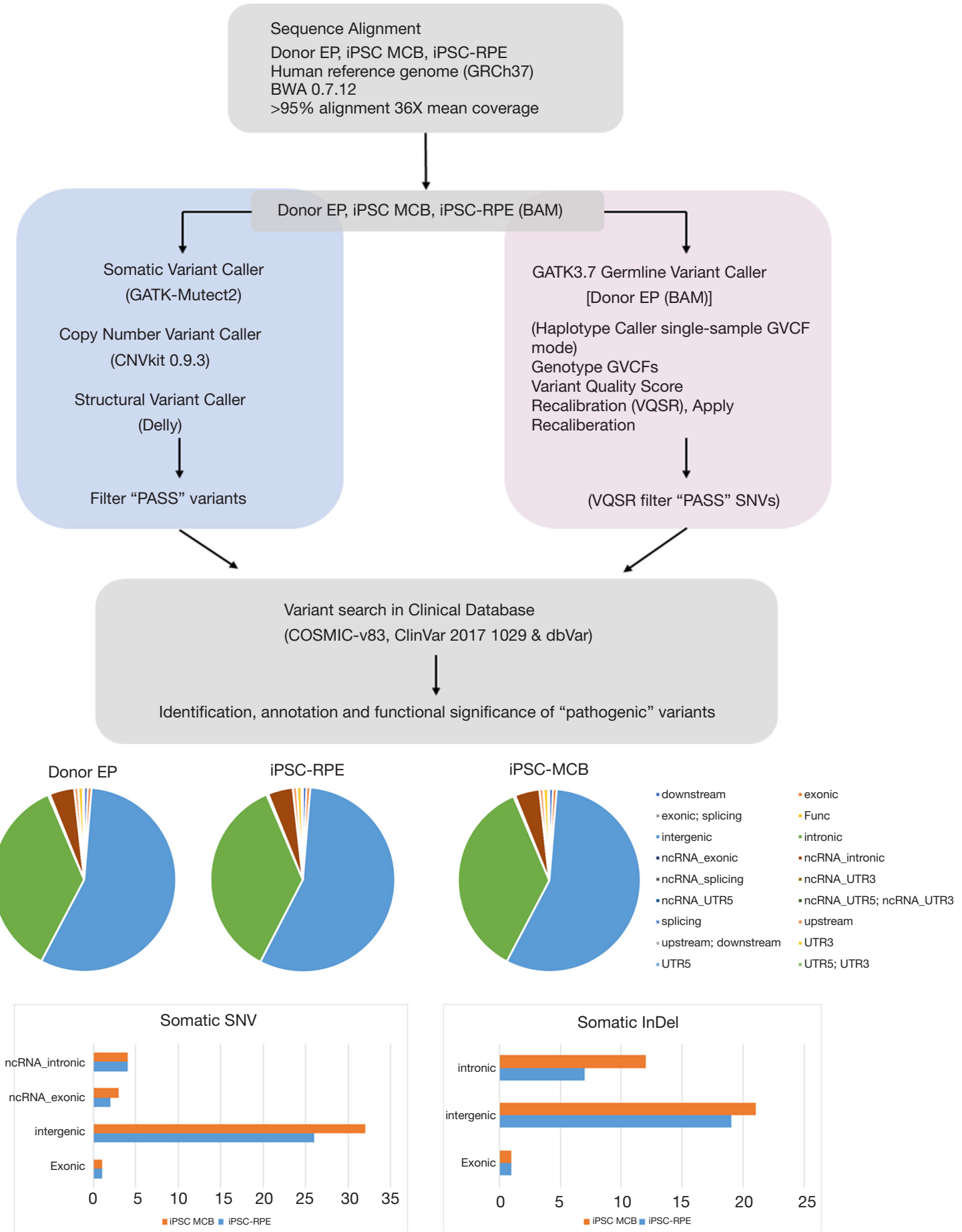

Figure 2 Whole-genome sequencing of donor EP, iPSC-RPE and iPSC MCB. (A) The flow chart describes donor EP, iPSC MCB, and iPSC-RPE whole-genome DNA sequence analysis pipelines for germline and somatic variant calling, filtration, and annotation. (B) Genome-wide functional annotation of germline and somatic SNVs based on their relative location in the genome. (C) The bar chart shows somatic variants of iPSC-RPE and iPSC MCB, iPSC-RPE: somatic SNVs and InDels for iPSC-RPE $v s$. donor EP; iPSC MCB: somatic SNVs and InDels for iPSC MCB vs. donor EP; SNV, single nucleotide variant; InDel, small insertion and deletion; Exonic, somatic nonsynonymous variant; ncRNA, noncoding RNA. 
A
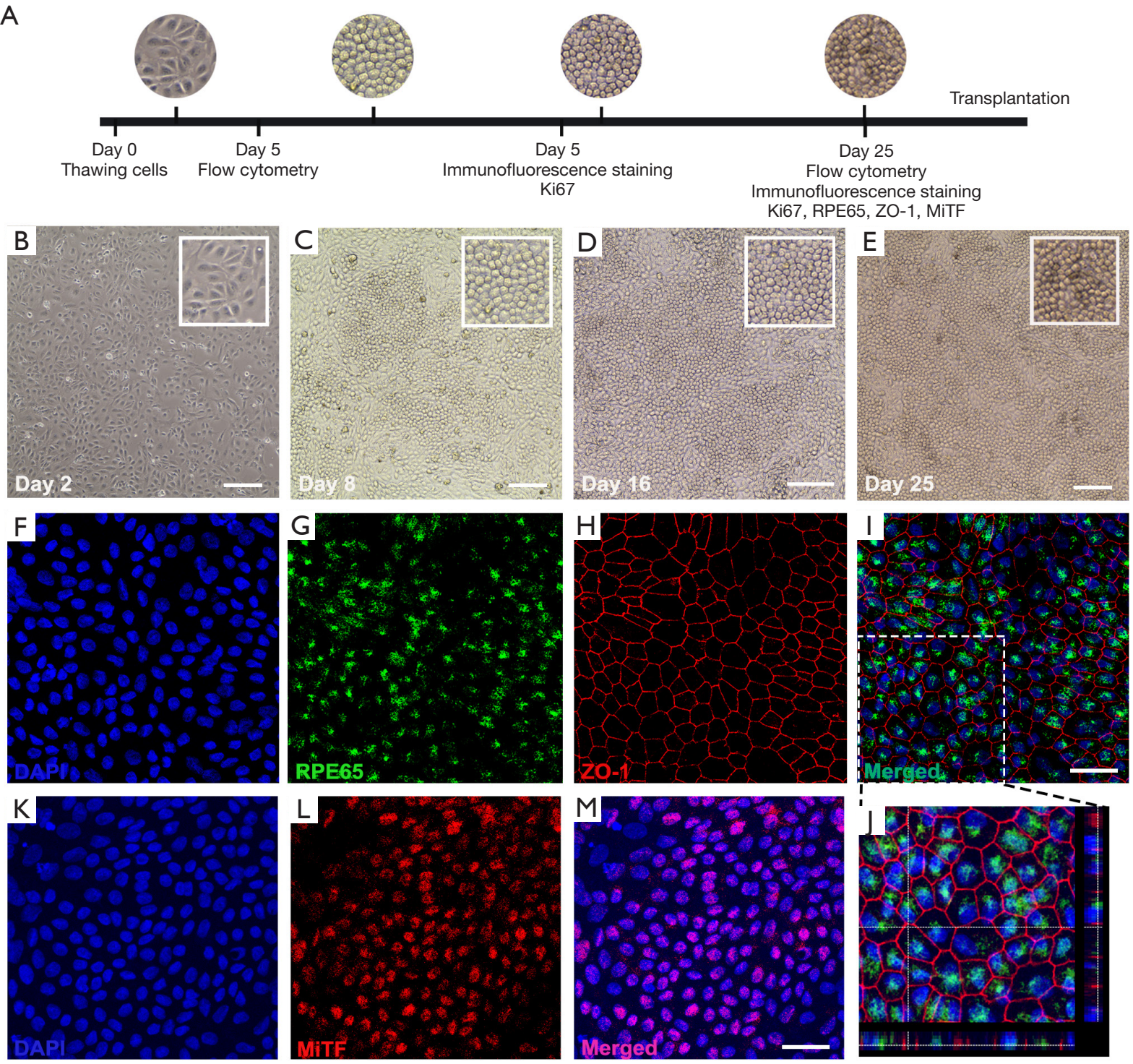

Figure 3 Maturation and characterization of human iRPE cells. (A) Scheme of iRPE cell culture and characterization methods. Phasecontrast images of human iRPE cells at 2 days (B), 8 days (C), 16 days (D) and 25 days (E) in culture. Magnified images are appended in the top right corners. Scale bars, $200 \mu \mathrm{m}(\mathrm{B}), 100 \mu \mathrm{m}$ (C-E). Representative immunofluorescence images of iRPE cells. iRPE cells expressed typical RPE markers, RPE65 (G), ZO-1 (H) and MiTF (L). (J) Magnified view of inset displays localization of RPE65 and ZO-1 to RPE cells. Cell nuclei (blue) were stained with DAPI (F, K), and merged images are shown in the panels (I, M). Scale bars, $25 \mu \mathrm{m}$.

$67+($ Figure $4 D, E, F)$, suggesting that the proliferative ability dramatically declined as the culture duration extended. Similar to immunofluorescence, flow cytometry showed approximately $17 \% \mathrm{Ki}-67$-positive cells in the iRPE cells on D5, while there were less than $1 \% \mathrm{Ki}-67$-positive cells on D24 (Figure 4H,I). In terms of proliferative ability, it might be safe to use human iRPE cells for cell replacement therapy.

\section{Safety assessment of human iRPE cells with NSG mice}

NSG mice, known as immunodeficient mice, were chosen to assess the potential risk of tumor formation following transplantation of human iRPE cells. NSG mice were purchased and kept for 1 week to help them adapt to the new conditions. Next, healthy NSG mice were randomly divided into 6 test groups: 5 groups with different doses 

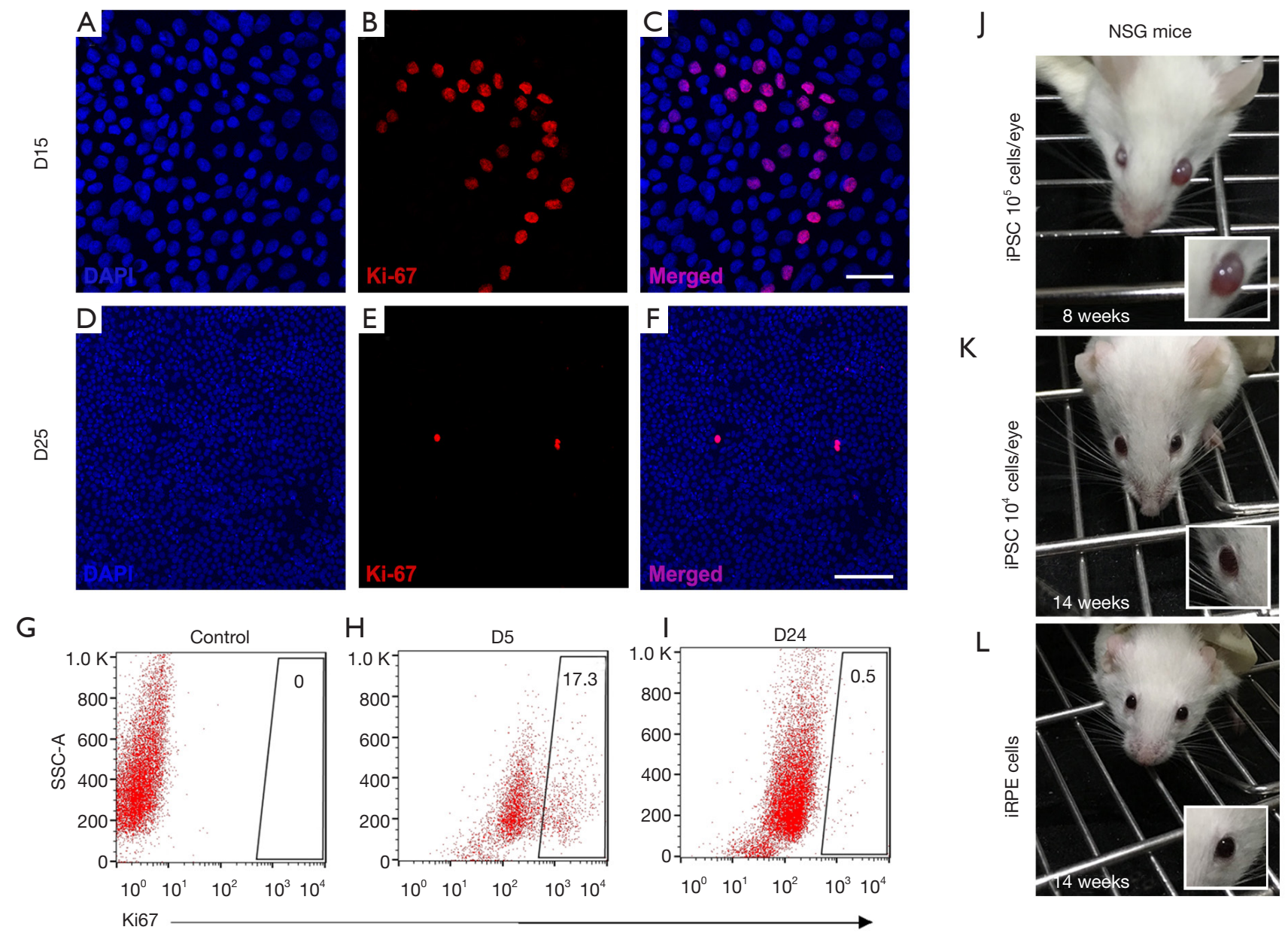

L

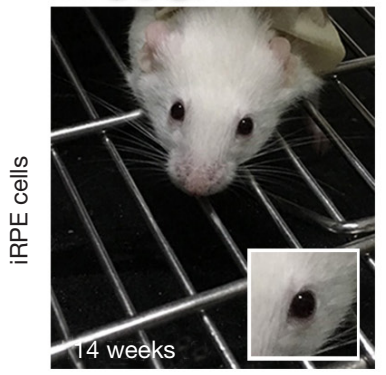

Figure 4 Safety assessment of human iRPE cells in vitro and in vivo. Immunofluorescence images show anti-Ki-67 antibody staining of cultured human iRPE cells at 15 days (B) and 25 days (E) after passage. Nuclei were (blue) stained with DAPI (A,D), and merged images are shown in the panels (C,F). Scale bars, $25 \mu \mathrm{m}(\mathrm{A}, \mathrm{B}, \mathrm{C})$, and $100 \mu \mathrm{m}(\mathrm{D}, \mathrm{E}, \mathrm{F})$. Flow cytometric analysis was used to determine the percentage of Ki-67-positive cells at 5 days $(\mathrm{H})$ and 24 days (I), indicating the proliferative ability of cultured iRPE cells. The percentage of Ki-67positive cells decreased significantly at 24 days compared with that of the cells at 5 days. iRPE cells at 5 days were not stained with antiKi-67 antibody as a control (G). Tumorigenesis tests of cultured iRPE cells and human iPSCs in immunodeficient NSG mice. No obvious positive characteristics were found in the iRPE-injected group (L). After different doses of human iPSC injection, eyeballs displayed tumor formation (J, K), n=8-10 eyes/group. Magnified photographs are appended in the bottom right corner.

of iPSCs $\left(10,10^{2}, 10^{3}, 10^{4}\right.$, and $5 \times 10^{5}$ cells/injection in groups 1, 2, 3, 4 and 5, respectively) and 1 human iRPE cell group with $5 \times 10^{5}$ cells/injection (Table 1). The cells were injected into the subretinal space, and the animals were consistently observed for 15 weeks. Each group consisted of 5 mice, except for group 2, in which one mouse died because of an anesthesia accident. Then, all NSG mice were observed twice per week and photographed once weekly. The eyes from group 5 exhibited abnormal proliferation (Figure 47 ) over 8 weeks after surgery, while the eyeballs from group 4 exhibited a similar but milder appearance in the 14th week (Figure 4K). However, no obviously positive characteristics were found in the other 4 groups, including the iRPE-injected group (Figure $4 L$ ). Taken together, these observations demonstrated that the transplantation of human iRPE cells is safe for replacement treatment.

\section{Imaging of transplanted cells in RCS rats}

To evaluate the influence of human iRPE cell 
Table 1 Tumorigenicity testing by subcutaneous and subretinal transplantation of human iPSC-RPE into NSG mice

\begin{tabular}{lcccc}
\hline Cell type & Number of cells transplanted & Number of eyes & Weeks to observe tumor (first to last) & Tumor formation \\
\hline hiPSC & $10^{1}$ cells & 10 & 15 weeks & None \\
hiPSC & $10^{2}$ cells & 8 & 15 weeks & None \\
hiPSC & $10^{3}$ cells & 10 & 15 weeks & None \\
hiPSC & $10^{4}$ cells & 10 & 15 weeks & 8th week \\
hiPSC & $5 \times 10^{5}$ cells & 10 & 15 weeks & None \\
hiRPE & $5 \times 10^{5}$ cells & 10 &
\end{tabular}

Tumor formation was only detected in NSG mice with $5 \times 10^{5}$ hiPSCs and $1 \times 10^{4}$ hiPSCs transplanted. No tumor formation was observed in the iRPE group. All NSG mice were monitored for 15 weeks. hiRPE, human retinal pigmented epithelium derived from induced pluripotent stem cells; hiPSC, human induced pluripotent stem cell.

transplantation into the degenerative retina, we injected an iRPE cell suspension into the subretinal space of RCS rats (Figure $5 A$ ). RCS rats are considered an ideal animal model for RPE transplantation and carry a mutation in the MERTK gene, resulting in damaged phagocytosis of RPE cells (42). Xenotransplantation of RPE cells into RCS rats was reported to induce inflammatory cellular infiltration and delay photoreceptor cell degeneration for only a short time (43). In this study, cyclosporine A was added to the drinking water of the animals until the experiment ended. As expected, we did not detect obvious clinical evidence of immunological rejection, including disc redness, edema, and vitreous or anterior chamber inflammation, in the iRPEtreated group and the sham group. Additionally, no tumor formation or abnormal proliferation from the transplanted cells was detected during the study.

Color fundus photographic imaging was performed to observe the placement of transplanted cells in vivo. The photographs on the 10th week after transplantation showed that dark pigments occurred near the optic disc and remained until 15 weeks after surgery (Figure 5B,C), while a similar phenomenon was not found in the eyes of the sham control group at either time point (Figure 5D,E). The images demonstrated that human iRPE cells were successfully transplanted into RCS rats and survived for at least 3 months.

\section{Therapeutic effect of iRPE cells on RCS rats}

To further assess the therapeutic effect, we used ERG responses to measure the visual function of the RCS rats after receiving subretinal iRPE cell transplantation (Figure $6 A$ ). The results were obtained from eyes receiving human iRPE cells, PBS-sham injections and no treatment. The recordings were made at the central retinal region close to the optic disc, which aimed at the dark pigment placement identified by build-in ophthalmoscopy. The focal ERG responses at 15 weeks after surgery showed that the iRPE-injected eyes achieved significantly better scotopic b-wave responses than the sham-injected and untreated eyes (Figure 6B). In addition, the a-wave responses of the iRPE-injected eyes indicated marginal rescue of visual performance compared to those of the untreated eyes, while the PBS-sham group had an effect similar to that of the untreated group (Figure 6C). Hence, the transplanted human iRPE cells rescued the visual function of RCS rats for 15 weeks under immunosuppressive conditions until the age of 18 weeks.

\section{Survival of transplanted cells in RCS rats}

Human nuclear (Hunu) specific antibody was used to identify the transplanted cells at 19 weeks after surgery. Hunupositive cells are predominantly distributed in the area adjacent to the outer nuclear layer (ONL) of the host retina. Previous reports showed that the ONL was completely lost in 3-month-old RCS rats (44), whereas at least 3-5 nuclear layers were preserved in the human iRPE cell-injected eyes (Figure 6D). Overall, the images demonstrated that human iRPE cells achieved long-term survival after transplantation into RCS rats and dramatically rescued photoreceptors.

\section{Discussion}

In an advanced stage, AMD progresses into two patterns: wet AMD and dry AMD. Some approaches targeting wet AMD, such as anti-vascular endothelial growth factor 
A

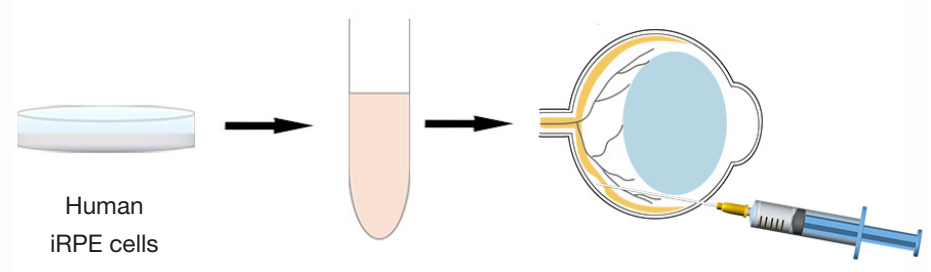

10 weeks

15 weeks
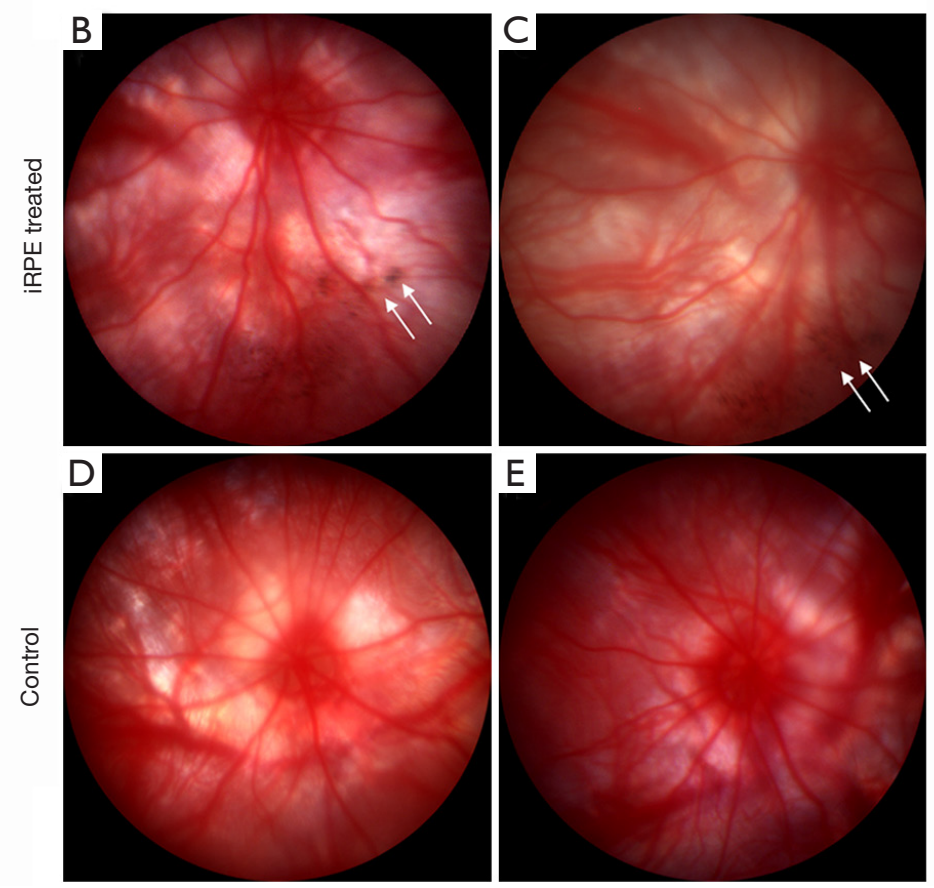

$\mathrm{E}$

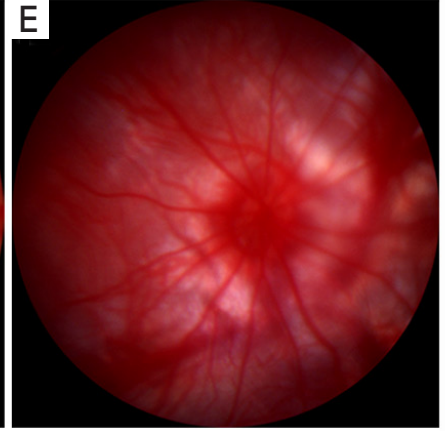

Figure 5 In vivo imaging of transplanted cells in RCS rats following surgery. (A) Diagram depicting the transplantation of cultured human iRPE cells. Color fundus photographic imaging of the transplanted human iRPE cells in RCS rats. (B,C,D,E) Dark pigments occurred occasionally near the optic disc at 10 weeks after surgery (B, arrows) and remained until 15 weeks (C, arrows), while the PBS-sham control group did not show a similar phenomenon at either stage (D,E).

(VEGF) treatment or surgical interference, have been demonstrated, whereas dry AMD remains incurable (2). Stem cell-based therapy has become a potential treatment for dry AMD and other forms of severe retinal degeneration. iRPE cells are similar to native RPE cells (45), with hexagonal monolayer epithelium and expression of classic human RPE markers, such as RPE65, ZO-1 and MiTF (Figure 3). These results are consistent with those of previous studies $(8,9,45)$. Other assays, including analyses of quantitative rod outer segment (ROS) phagocytosis, gene expression, secretion of pigment epithelium-derived factor (PEDF) or retinoid metabolism, have not been performed $(46,47)$. It was estimated that approximately $10^{5}$ RPE cells were required to cover the macular area (46); however, there are no unified criteria for the quantity, quality and developmental stage of iPSC-RPE cells used for replacement treatment. Such criteria should be considered before industrial application.

Another critical problem for human iRPE cell transplantation is the potential risk of tumor formation, which is a key factor in safety assessment for stem cellderived cell replacement therapy. In fact, mutations in human iPSCs are a concern, but research has shown that the mutation of iPSCs via the reprogramming of somatic cells exhibits a 10 -fold lower rate than that of the corresponding somatic cells (48). A recent study demonstrated that clinically recognized mutations were absent in clinicalgrade human PSCs, and pathological mutations were 
A

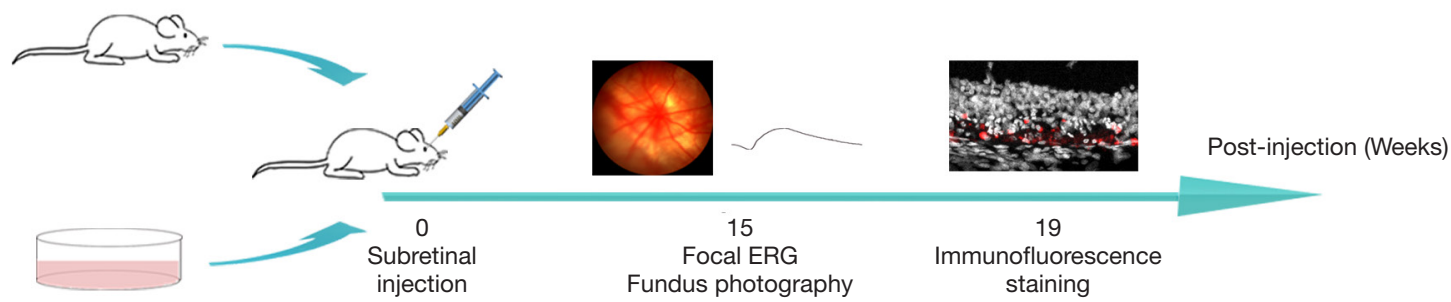

B

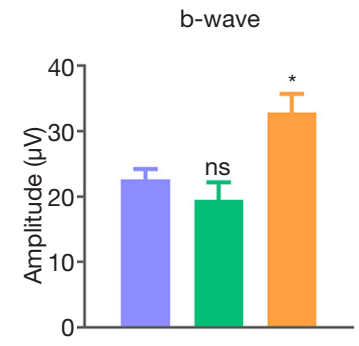

C

a-wave

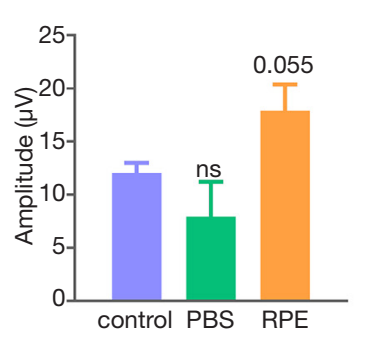

D

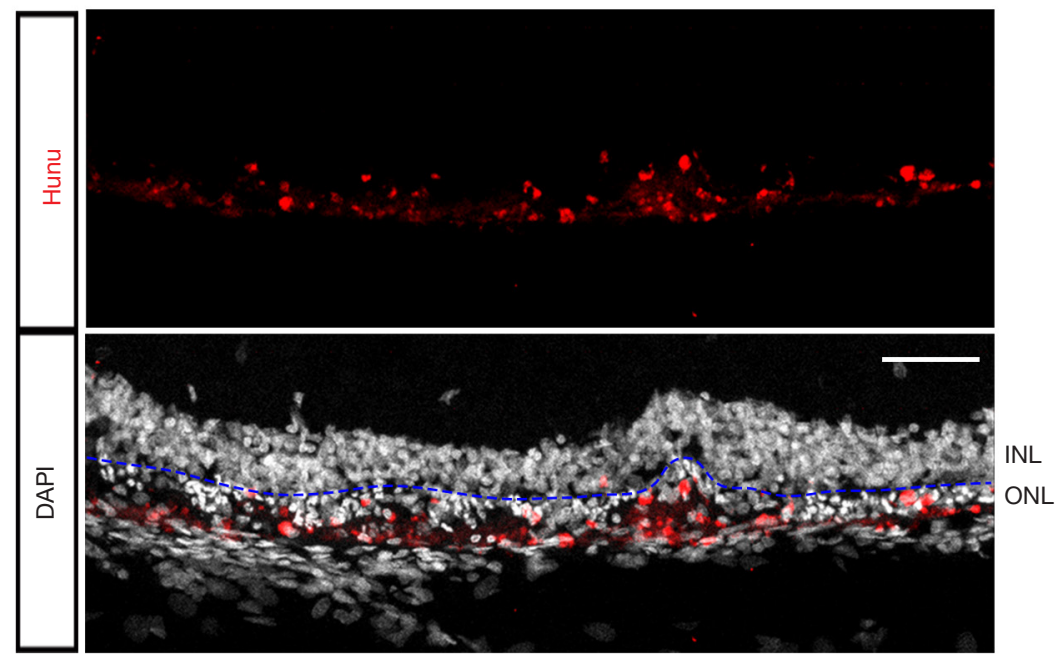

Figure 6 Functional assessment and histological analysis following transplantation. Focal electroretinogram was used to measure the visual function of RCS rats at 15 weeks after surgery. (A) Sketch depicting the assessment of the efficacy of cultured iRPE cell replacement therapy in RCS rats. (B) The iRPE-injected group achieved significantly better b-wave responses than the sham group when compared with the untreated group at 15 weeks after transplantation. (C) The iRPE-injected eyes exhibited marginally rescued visual performance, while the PBS-sham group exhibited a similar effect to the untreated group for scotopic a-wave responses. Error bars indicate s.e.m., $\mathrm{N}_{\text {crtr }}=6$ replicates, $\mathrm{N}_{\mathrm{PBS}}=5$ replicates, $\mathrm{N}_{\mathrm{iRPE}}=8$ replicates, ${ }^{*} \mathrm{P}<0.05$ for unpaired Student's $t$-test compared to the untreated group. (D) Representative images of immunostained retinal sections showing the locations of transplanted cell infiltration and deep ONL at 19 weeks after surgery. Human iRPE cell nuclei were stained with human nuclear-specific antibody (red). Cell nuclei were stained with DAPI (gray), and merged images are shown in panels. The blue dotted line is between the INL and ONL. Scale bar, $50 \mu \mathrm{m}$. INL, inner nuclear layer; ONL, outer nuclear layer.

extremely low even if the culture was prolonged in vitro (49). In addition, several immunodeficient animals have been used for tumorigenicity tests of human iPSC-derived cell products, and no evidence of abnormal proliferation has been detected $(16,17)$. The U.S. Food and Drug Administration (FDA) commentary report suggested that tumorigenicity tests needed to be tailored for specific cellular products (50). For these reasons, we examined the proliferative ability of iRPE cells both in vitro and in vivo (Figure 4). In this context, the proliferative ability of transplanted cells was reflected by $\mathrm{Ki}-67$ protein expression, which was detected by qualitative and quantitative methods.
Additionally, we injected human iRPE cells into the subretinal space of immunodeficient NSG mice, and no tumor formation was observed until 15 weeks after surgery, indicating that the cultured cells are safe enough for cell replacement therapy. In fact, no tumor formation has been reported in clinical research until now.

Since we hope that transplanted iRPE cells can function as well as natural RPE cells, the survival of iRPE cells is important. The survival duration of transplanted cells is related to both the microenvironment of hosts and the status of injected cells. In consideration of immunological rejection, autologous iRPE cells are considered ideal 
donors for replacement therapy. An encouraging clinical study performed autologous iRPE cell transplantation for one wet-AMD patient who did not receive immunosuppressants, and no serious symptoms were observed (19). However, contrasting findings have been reported. For instance, autologous iPSC-derived cells could cause immunological rejection in mice (51). Allogenic iRPE cell transplantation resulted in complement activation in monkeys (52). In addition, in rhesus macaques, allogenic iRPE transplants were undetected by 3 weeks following surgery, accompanied by disruption of the host choroid and RPE, possibly by immunity-mediated rejection (9). A previous study also showed that iRPE cells could lead to the inhibition of T-cell activation (53). Therefore, the use of immunosuppressants should be taken into consideration prior to clinical application. The type, form (topical or systemic administration), frequency and period of drugs all need more exploration in future studies.

It is important to determine whether transplants can rescue visual function or slow the degenerative process. The transplanted human iRPE cells were obtained in a GMPgrade cell culture facility in our study. The head-tracking response, in a previous study, was used to assess global retinal function after delivering iRPE cells into RCS rats (18) and was not able to reflect the focal visual performance rescued by the transplanted cells. Our data showed that transplants can dramatically rescue visual function. However, the mechanism whereby heterogenic human iRPE cells rescue visual function remains unclear, and it is unclear whether some growth factors or other secretions remain functional when transplants are not detected. The relationship between the visual results and the optimal dosage or therapeutic window needs to be explored further in follow-up studies.

Many clinical trials on AMD treatment based on iRPE cell transplantation have been performed by research institutions or companies in recent years. However, most of these studies are still in phase 1 or 2, and the number of subjects is not sufficient (18). More clinical trials are needed in different countries and regions under safe circumstances. Furthermore, some essential issues, such as the surgical method, the optimal dose, immunity rejection and other adverse events, should be considered (54). Gene correction also provides a new prospect for autologous iRPE cell replacement therapies, which might offer a potential approach for inherited or acquired disease with the help of genome editing tools $(55,56)$. In summary, we look forward to the establishment of an iPSC bank and its clinical application in the future.

\section{Conclusions}

In this study, we demonstrated that induced pluripotent stem cell-derived retinal pigment epithelium (iPSC-RPE or iRPE) was similar to native RPE. Then, we studied the potential risk of tumor formation and efficacy of rescuing visual function for human iRPE cell replacement therapy. The results suggested that transplanted cells could survive for at least 19 weeks in the host. More importantly, transplanted human iRPE cells can rescue photoreceptors and slow disease progression, although the mechanism remains unclear. We look forward to the establishment of an iRPE cell bank and its clinical applications in the coming years.

\section{Acknowledgments}

Funding: This study was partly supported by the Beijing Natural Science Foundation (Z200014) and National Key R\&D Program of China (2017YFA0105300).

\section{Footnote}

Reporting Checklist: The authors have completed the ARRIVE reporting checklist. Available at http://dx.doi. org/10.21037/atm-20-4707

Data Sharing Statement: Available at http://dx.doi. org/10.21037/atm-20-4707

Conflicts of Interest: All authors have completed the ICMJE uniform disclosure form (available at http://dx.doi. org/10.21037/atm-20-4707). The authors have no conflicts of interest to declare.

Ethical Statement: The authors are accountable for all aspects of the work in ensuring that questions related to the accuracy or integrity of any part of the work are appropriately investigated and resolved. Experiments were performed under a project license (\#NC2018R012) granted by Institutional Ethics Committee in compliance with institutional guidelines for the care and use of animals.

Open Access Statement: This is an Open Access article distributed in accordance with the Creative Commons Attribution-NonCommercial-NoDerivs 4.0 International 
License (CC BY-NC-ND 4.0), which permits the noncommercial replication and distribution of the article with the strict proviso that no changes or edits are made and the original work is properly cited (including links to both the formal publication through the relevant DOI and the license). See: https://creativecommons.org/licenses/by-nc-nd/4.0/.

\section{References}

1. Wong WL, Su X, Li X, et al. Global prevalence of age-related macular degeneration and disease burden projection for 2020 and 2040: a systematic review and meta-analysis. Lancet Glob Health 2014;2:e106-16.

2. Jin ZB, Gao ML, Deng WL, et al. Stemming retinal regeneration with pluripotent stem cells. Prog Retin Eye Res 2019;69:38-56.

3. Strauss $O$. The retinal pigment epithelium in visual function. Physiol Rev 2005;85:845-81.

4. Algvere PV, Berglin L, Gouras P, et al. Transplantation of RPE in age-related macular degeneration: observations in disciform lesions and dry RPE atrophy. Graefes Arch Clin Exp Ophthalmol 1997;235:149-58.

5. Binder S, Krebs I, Hilgers RD, et al. Outcome of transplantation of autologous retinal pigment epithelium in age-related macular degeneration: a prospective trial. Invest Ophthalmol Vis Sci 2004;45:4151-60.

6. van Meurs JC, ter Averst E, Hofland LJ, et al. Autologous peripheral retinal pigment epithelium translocation in patients with subfoveal neovascular membranes. Br J Ophthalmol 2004;88:110-3.

7. Vugler A, Carr AJ, Lawrence J, et al. Elucidating the phenomenon of HESC-derived RPE: anatomy of cell genesis, expansion and retinal transplantation. Exp Neurol 2008;214:347-61.

8. Sun J, Mandai M, Kamao H, et al. Protective effects of human iPS-derived retinal pigmented epithelial cells in comparison with human mesenchymal stromal cells and human neural stem cells on the degenerating retina in $\mathrm{rd} 1$ mice. Stem Cells 2015;33:1543-53.

9. McGill TJ, Stoddard J, Renner LM, et al. Allogeneic iPSC-derived RPE cell graft failure following transplantation into the subretinal space in nonhuman primates. Invest Ophthalmol Vis Sci 2018;59:1374-83.

10. Sugita S, Makabe K, Fujii S, et al. Detection of retinal pigment epithelium-specific antibody in iPSC-derived retinal pigment epithelium transplantation models. Stem Cell Reports 2017;9:1501-15.

11. Lund RD, Wang S, Klimanskaya I, et al. Human embryonic stem cell-derived cells rescue visual function in dystrophic RCS rats. Cloning Stem Cells 2006;8:189-99.

12. Idelson M, Alper R, Obolensky A, et al. Directed differentiation of human embryonic stem cells into functional retinal pigment epithelium cells. Cell Stem Cell 2009;5:396-408.

13. Davis RJ, Alam NM, Zhao C, et al. The Developmental stage of adult human stem cell-derived retinal pigment epithelium cells influences transplant efficacy for vision rescue. Stem Cell Reports 2017;9:42-9.

14. Carr AJ, Vugler AA, Hikita ST, et al. Protective effects of human iPS-derived retinal pigment epithelium cell transplantation in the retinal dystrophic rat. PLoS One 2009; 4:e8152.

15. Lu B, Malcuit C, Wang S, et al. Long-term safety and function of RPE from human embryonic stem cells in preclinical models of macular degeneration. Stem Cells 2009;27:2126-35.

16. Kanemura H, Go MJ, Shikamura M, et al. Tumorigenicity studies of induced pluripotent stem cell (iPSC)-derived retinal pigment epithelium (RPE) for the treatment of agerelated macular degeneration. PLoS One 2014;9:e85336.

17. Kawamata S, Kanemura H, Sakai N, et al. Design of a tumorigenicity test for induced pluripotent stem cell (iPSC)-derived cell products. J Clin Med 2015;4:159-71.

18. Diao L, Fang PF. Clinical progress of cell therapy in treating age-related macular degeneration. Clinical Trials in Degenerative Diseases 2019;4:37-42.

19. Mandai M, Watanabe A, Kurimoto Y, et al. Autologous induced stem-cell-derived retinal cells for macular degeneration. N Engl J Med 2017;376:1038-46.

20. Maeda T, Lee MJ, Palczewska G, et al. Retinal pigmented epithelial cells obtained from human induced pluripotent stem cells possess functional visual cycle enzymes in vitro and in vivo. J Biol Chem 2013;288:34484-93.

21. Sharma R, Khristov V, Rising A, et al. Clinical-grade stem cell-derived retinal pigment epithelium patch rescues retinal degeneration in rodents and pigs. Sci Transl Med 2019;11:eaat5580.

22. Buchholz DE, Pennington BO, Croze RH, et al.Rapid and efficient directed differentiation of human pluripotent stem cells into retinal pigmented epithelium. Stem Cells Transl Med 2013;2:384-93.

23. Chambers SM, Fasano CA, Papapetrou EP, et al.Highly efficient neural conversion of human ES and iPS cells by dual inhibition of SMAD signaling. Nat Biotechnol 2009;27:275-80.

24. Nistor G, Seiler MJ, Yan F, et al.Three-dimensional 
early retinal progenitor 3D tissue constructs derived from human embryonic stem cells. J Neurosci Methods 2010;190:63-70.

25. Osakada F, Ikeda H, Sasai Y, et al. Stepwise differentiation of pluripotent stem cells into retinal cells. Nat Protoc 2009;4:811-24.

26. Yu J, Chau KF, Vodyanik MA, et al. Efficient feeder-free episomal reprogramming with small molecules. PLoS One 2011;6:e17557.

27. Alvarez-Palomo B, Vives J, Casaroli-Marano RPP, et al. Adapting cord blood collection and banking standard operating procedures for HLA-homozygous induced pluripotent stem cells production and banking for clinical application. J Clin Med 2019;8:476.

28. Awe JP, Lee PC, Ramathal C, et al. Generation and characterization of transgene-free human induced pluripotent stem cells and conversion to putative clinicalgrade status. Stem Cell Res Ther 2013;4:87.

29. Baghbaderani BA, Tian X, Neo BH, et al. cGMPmanufactured human induced pluripotent stem cells are available for pre-clinical and clinical applications. Stem Cell Reports 2015;5:647-59.

30. Crook JM, Peura TT, Kravets L, et al. The generation of six clinical-grade human embryonic stem cell lines. Cell Stem Cell 2007;1:490-4.

31. Gu Q, Wang J, Wang L, et al. Accreditation of biosafe clinical-grade human embryonic stem cells according to Chinese regulations. Stem Cell Reports 2017;9:366-80.

32. Haase A, Glienke W, Engels L, et al. GMP-compatible manufacturing of three iPS cell lines from human peripheral blood. Stem Cell Res 2019;35:101394.

33. Sullivan S, Stacey GN, Akazawa C, et al. Quality control guidelines for clinical-grade human induced pluripotent stem cell lines. Regen Med 2018;13:859-66.

34. Wiley LA, Anfinson KR, Cranston CM, et al. Generation of xeno-free, cGMP-compliant patient-specific iPSCs from skin biopsy. Curr Protoc Stem Cell Biol 2017;42:4A.12.14A.12.14.

35. Wiley LA, Burnight ER, DeLuca AP, et al. cGMP production of patient-specific iPSCs and photoreceptor precursor cells to treat retinal degenerative blindness. Sci Rep 2016;6:30742.

36. Avior Y, Eggan K, Benvenisty N. Cancer-related mutations identified in primed and naive human pluripotent stem cells. Cell Stem Cell 2019;25:456-61.

37. Canham MA, Van Deusen A, Brison DR, et al. The molecular karyotype of 25 clinical-grade human embryonic stem cell lines. Sci Rep 2015;5:17258.
38. Garitaonandia I, Gonzalez R, Christiansen-Weber T, et al. Neural stem cell tumorigenicity and biodistribution assessment for Phase I clinical trial in Parkinson's disease. Sci Rep 2016;6:34478.

39. Goh PA, Caxaria S, Casper C, et al. A systematic evaluation of integration free reprogramming methods for deriving clinically relevant patient specific induced pluripotent stem (iPS) cells. PLoS One 2013;8:e81622.

40. Huang XF, Wu J, Lv JN, et al. Identification of falsenegative mutations missed by next-generation sequencing in retinitis pigmentosa patients: a complementary approach to clinical genetic diagnostic testing. Genet Med 2015;17:307-11.

41. Schlaeger TM, Daheron L, Brickler TR, et al. A comparison of non-integrating reprogramming methods. Nat Biotechnol 2015;33:58-63.

42. Mullen RJ, LaVail MM. Inherited retinal dystrophy: primary defect in pigment epithelium determined with experimental rat chimeras. Science 1976;192:799-801.

43. Grisanti S, Szurman P, Jordan J, et al. Xenotransplantation of retinal pigment epithelial cells into RCS rats. Jpn J Ophthalmol 2002;46:36-44.

44. Dowling JE, Sidman RL. Inherited retinal dystrophy in the rat. J Cell Biol 1962;14:73-109.

45. Kamao H, Mandai M, Okamoto S, et al. Characterization of human induced pluripotent stem cell-derived retinal pigment epithelium cell sheets aiming for clinical application. Stem Cell Reports 2014;2:205-18.

46. Buchholz DE, Hikita ST, Rowland TJ, et al. Derivation of functional retinal pigmented epithelium from induced pluripotent stem cells. Stem Cells 2009;27:2427-34.

47. Blenkinsop TA, Saini JS, Maminishkis A, et al. Human adult retinal pigment epithelial stem cell-derived RPE monolayers exhibit key physiological characteristics of native tissue. Invest Ophthalmol Vis Sci 2015;56:7085-99.

48. Rouhani FJ, Nik-Zainal S, Wuster A, et al. Mutational history of a human cell lineage from somatic to induced pluripotent stem cells. PLoS Genet 2016;12:e1005932.

49. Thompson O, von Meyenn F, Hewitt Z, et al. Low rates of mutation in clinical grade human pluripotent stem cells under different culture conditions. Nat Commun 2020;11:1528.

50. Bailey AM. Balancing tissue and tumor formation in regenerative medicine. Sci Transl Med 2012;4:147fs28.

51. Zhao T, Zhang ZN, Rong Z, et al. Immunogenicity of induced pluripotent stem cells. Nature 2011;474:212-5.

52. Sugita S, Makabe K, Fujii S, et al. Detection of complement activators in immune attack eyes after iPS- 
derived retinal pigment epithelial cell transplantation. Invest Ophthalmol Vis Sci 2018;59:4198-209.

53. Sugita S, Kamao H, Iwasaki Y, et al. Inhibition of T-cell activation by retinal pigment epithelial cells derived from induced pluripotent stem cells. Invest Ophthalmol Vis Sci 2015;56:1051-62.

54. Xiang P, Wu KC, Zhu Y, et al. A novel Bruch's membranemimetic electrospun substrate scaffold for human retinal pigment epithelium cells. Biomaterials 2014;35:9777-88.

Cite this article as: Zhang $\mathrm{H}$, Su B, Jiao L, Xu ZH, Zhang CJ, Nie J, Gao ML, Zhang YV, Jin ZB. Transplantation of GMPgrade human iPSC-derived retinal pigment epithelial cells in rodent model: the first pre-clinical study for safety and efficacy in China. Ann Transl Med 2021;9(3):245. doi: 10.21037/atm-204707
55. Li Y, Chan L, Nguyen HV, et al. Personalized medicine: cell and gene therapy based on patient-specific iPSCderived retinal pigment epithelium cells. Adv Exp Med Biol 2016;854:549-55.

56. Deng WL, Gao ML, Lei XL, et al. Gene correction reverses ciliopathy and photoreceptor loss in iPSC-derived retinal organoids from retinitis pigmentosa patients. Stem Cell Reports 2018;10:1267-81. 


\section{Supplementary}

Table S1 Qualification of GMP-compatible iPSC cryo-banks

\begin{tabular}{|c|c|c|c|c|c|c|}
\hline Attribute & Test & Method & Acceptance criteria & SCB & MCB & WCB \\
\hline \multirow{2}{*}{ Identity } & Pluripotent markers & Immuno-cytochemistry & $\begin{array}{l}\text { OCT } 4+>80 \%, \\
\text { NANOG }+>80 \%\end{array}$ & $\bullet$ & $\bullet$ & $\bullet$ \\
\hline & STR & STR profiling & Identical to donor cells & $\bullet$ & $\bullet$ & $\bullet$ \\
\hline Viability & Viability & $\begin{array}{l}\text { Dye exclusion cell } \\
\text { counting }\end{array}$ & $>60 \%$ & $\bullet$ & $\bullet$ & $\bullet$ \\
\hline \multirow[t]{3}{*}{ Genetic stability } & Karyotype & G-banding & Normal diploid & $\bullet$ & $\bullet$ & - \\
\hline & $\begin{array}{l}\text { Residual vector } \\
\text { testing }\end{array}$ & PCR & Negative & $\bullet$ & $\bullet$ & $\circ$ \\
\hline & Cancer gene mutation & WGS/WES & Negative & $\circ$ & • (WGS) & - (WES) \\
\hline Potency & Pluripotency & Teratoma formation & $\begin{array}{l}\text { Demonstration of tissues } \\
\text { from all three germ layers }\end{array}$ & $\circ$ & $\bullet$ & ○ \\
\hline \multirow[t]{2}{*}{ Microbiological safety } & Bacteria & Culture & Negative & $\bullet$ & $\bullet$ & $\bullet$ \\
\hline & Fungi & Culture & Negative & • & - & - \\
\hline
\end{tabular}

